\title{
A Radiation Hybrid Map of the Region on Human Chromosome 22 Containing the Neurofibromatosis Type 2 Locus
}

\author{
Kelly A. Frazer, * Michael Boehnke, † Marcia L. Budarf, $\ddagger$ Roger K. Wolff, $§$ Beverly S. Emanuel, $\ddagger$

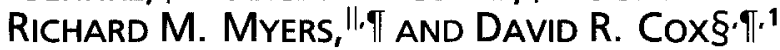 \\ Departments of *Anatomy, §Psychiatry, "Biochemistry and Biophysics, and "Physiology, University of California, San Francisco, \\ California, 94143; ¥Pediatrics and Human Genetics, University of Pennsylvania School of Medicine and Children’s Hospital \\ of Philadelphia, Philadelphia, Pennsylvania 19104; and †Biostatistics, School of Public Health, \\ University of Michigan, Ann Arbor, Michigan 48109 \\ Received January 30, 1992; revised July 20, 1992
}

\begin{abstract}
We describe a high-resolution radiation hybrid map of the region on human chromosome 22 containing the neurofibromatosis type 2 (NF2) gene. Eighty-five hamster-human somatic cell hybrids generated by $\mathrm{X}$-irradiation and cell fusion were used to generate the radiation hybrid map. The presence or absence of 18 human chromosome 22-specific markers was determined in each hybrid by using Southern blot hybridization. Sixteen of the 18 markers were distinguishable by $X$-ray breakage in the radiation hybrids. Analysis of these data using two different mathematical models and two different statistical methods resulted in a single framework map consisting of 8 markers ordered with odds greater than 1000:1. The remaining nonframework markers were all localized to regions consisting of two adjoining intervals on the framework map with odds greater than 1000:1. Based on the RH map, the NF2 region of chromosome 22 , defined by the flanking markers D22S1 and D22S28, is estimated to span a physical distance of approximately $6 \mathrm{Mb}$ and is the most likely location for 9 of the 18 markers studied: D22S33, D22S41, D22S42, D22S46, D22S56, LIF, D22S37, D22S44, and D22S15. @ 1992 Academic Press, Inc.
\end{abstract}

\section{INTRODUCTION}

Neurofibromatosis type 2 (NF2) is an autosomal dominant disorder associated with the development of bilateral acoustic neuromas and other nervous system tumors, including meningiomas, gliomas, and neurofibromas. The growth of these tumors in patients with NF2 can have severe consequences, leading to deafness, vertigo, paresis, and death in the third to fourth decade of life (Martuza and Eldridge, 1988). The observation of common nonrandom loss and structural rearrangements of chromosome 22 in acoustic neuromas and meningio-

${ }^{1}$ To whom correspondence should be addressed at the University of California, 401 Parnassus Avenue, P.O. Box 0984, San Francisco, CA 94143-0984. mas first suggested that the NF2 gene might be present on this chromosome (Zankl and Zang, 1972; Seizinger et $a l ., 1986,1987)$. More recently, tumor deletion studies and genetic linkage analyses have indicated that the NF2 locus is a tumor suppressor gene located within a 13-cM region on the long arm of chromosome 22 , between the flanking markers D22S1 and D22S28 (Rouleau et al., 1990). Genetic linkage studies have localized several polymorphic markers to the NF2 region of chromosome 22, between D22S1 and D22S28 (Rouleau et al., 1989; Dumanski et al., 1991). In addition, physical mapping studies have used somatic cell hybrids containing defined portions of chromosome 22 to assign a number of probes to the NF2 region (Budarf et al., 1991, Delattre et al., 1991). However, the orders and distances between many of these markers are not completely defined, and the published maps of the NF2 region are crude in molecular terms.

In this study we have used radiation hybrid $(\mathrm{RH})$ mapping to construct a fine-structure map of the NF2 region on chromosome 22 . $\mathrm{RH}$ mapping is a somatic cell genetic technique in which the frequency of $\mathrm{X}$-ray breakage between chromosome-specific DNA markers is analyzed statistically to determine the order and distance between these markers along the chromosome (Cox et $a l ., 1990)$. A distinct advantage of $\mathrm{RH}$ mapping over genetic linkage mapping is that nonpolymorphic as well as polymorphic DNA markers can be ordered at a very high level of resolution. Although $\mathrm{RH}$ mapping is a statistical rather than a physical mapping method, the frequency of X-ray breakage between two markers has been found to be directly related to the physical distance between them, such that at a dose of 8000 rads of $X$ rays, $1 \%$ breakage between markers corresponds to a physical distance of approximately $50 \mathrm{~kb}$ (Cox et al., 1990; Burmeister et al., 1991).

Several different mathematical models and methods for the statistical analysis of $\mathrm{RH}$ mapping data have been described, each with its own strengths and weaknesses (Cox et al., 1990; Boehnke et al., 1991; Falk, 1991; 
Lawrence et al., 1991; Bishop and Crockford, 1992; Chakravarti and Reefer, 1992; Green, 1992). However, for the limited number of data sets analyzed to date, no single model or method of analysis has been shown to be clearly preferred in all cases. Models that assume a single retention frequency for all markers in a set of radiation hybrids are attractive, since they provide mathematically simple means for estimating the distance between markers as well as the likelihood of one map order versus another. However, for those data sets in which the retention of different markers is clearly not identical, it is not known whether the use of a single retention frequency model will lead to incorrect maps.

In this report we use two different mathematical models for analyzing RH data: the equal retention model, which assumes a single retention frequency for all markers in the radiation hybrids, and the unequal retention model, which permits a different retention frequency for each marker. In addition, we use two different statistical estimation procedures to analyze the data: the method of moments and maximum likelihood analysis. Despite the fact that the marker retention is not identical for the different markers in this data set, the use of the equal retention model and the method of moments results in a framework map of 8 markers ordered at $1000: 1$ odds that is the same as that obtained using the unequal retention model and the method of moments. Analysis of this data set using the equal retention model and a maximum likelihood estimation approach yields the same framework map as the method of moments estimation procedure. In addition, the maximum likelihood approach results in a comprehensive map that gives the most likely order for all 16 distinguishable loci. Our RH map assigns new markers to the NF2 region and provides additional order and distance information for markers previously localized to this segment of human chromosome 22 .

\section{MATERIALS AND METHODS}

DNA probes. The chromosome 22 DNA marker loci used in this study, with the probe that recognizes each locus listed in parentheses following that locus, were D22S33 (pH4), D22S36 (pH11), D22S37 (pH13), D22S41 (pH20), D22S42 (pH22), D22S44 (pH35), D22S46 (pH43), D22S47 (pH59), D22S48 (pH60), and D22S56 (pH97b). These probes were isolated from a flow-sorted library (LL22NS01) constructed at the Biomedical Sciences Division, Lawrence Livermore National Laboratory (Livermore, CA) (Budarf et al., 1991). DNA marker D22S28 (W23C) was isolated from the same library described above (Rouleau et al., 1989). The following genes and anonymous markers were also used: platelet-derived growth factor $\beta$ polypeptide chain gene, PDGFB (pA-csis) (gift from Dan Mirda); myoglobin gene, MB (pHM27.B2.9) (Weller et al., 1984); leukemia inhibitory factor gene, LIF (pC4.7) (Lowe et al., 1989); D22S1 (pMS3-18) (Barker et al., 1984); and D22S15 (DP22) (Rouleau et al., 1988). The breakpoint cluster region gene (BCR) and a BCR-like locus (BCRL2), each of which maps to a distinct region of 22q11, were detected with a single probe derived from the $3^{\prime}$ end of a BCR cDNA clone (Croce $e t$ al., 1987; Budarf et al., 1988).

Cell lines and culture conditions. Cell line EYEF3A6 (GM10027) is a Chinese hamster-human hybrid cell line containing an intact human chromosome 22 and fragments of human chromosomes 15 and 19
(Van Keuren et al., 1987; Ledbetter et al., 1990). EYEF3A6 cells were grown in Ham's F12 medium supplemented with $10 \%$ dialyzed fetal calf serum (FCS), penicillin, and streptomycin. 380-6, a hypoxanthine-guanine phosphoribosyltransferase (HPRT)-deficient hamster cell line, was cultured in Dulbecco's modified Eagle's medium (DMEM) containing 10\% FCS, penicillin, and streptomycin.

Production of radiation hybrids. $\mathrm{X}$-irradiation and cell fusion were performed as previously described (Cox et al., 1989). Briefly, EYEF3A6 cells were irradiated with 8000 rads of $X$ rays and fused in a 1:1 ratio with nonirradiated HPRT-deficient $380-6$ hamster cells by polyethylene glycol. The fused cells were then cultured in HAT medium (DMEM plus $100 \mu M$ hypoxanthine, $1 \mu M$ aminopterin, and 12 $\mu M$ thymidine) to eliminate the nonhybrid $380-6$ cells and to select for hybrids retaining the hamster HPRT gene from the irradiated EYEF3A6 cells. Two to three weeks after fusion, an average of one EYEF3A6 $\times 380-6$ radiation hybrid clone per plate was observed, indicating a hybrid formation efficiency of approximately one hybrid per $1.5 \times 10^{5}$ recipient $380-6$ cells. No colonies formed from either $10^{7}$ irradiated, nonfused EYEF3A6 cells or 10 7 unfused 380-6 cells grown in HAT medium. A total of 130 independent colonies that grew under HAT selection were expanded in HAT medium. DNA was isolated from 86 of the fastest growing hybrids and was analyzed for the retention of human chromosome 22 DNA markers by Southern blot analysis as described below. Southern blot data from one of the 86 hybrids were not included in the statistical analysis due to inconsistent results for multiple markers on different blots; thus the map is based on results using 85 radiation hybrids. In addition, it should be noted that not all hybrids could be scored reliably for all markers, resulting in some missing data (see Tables 1 and 2).

Southern blot analysis and hybridization. Genomic DNA was isolated from cultured cells as previously described (Cox et al., 1990), digested to completion with HindIII, electrophoresed through $1 \%$ agarose gels, and transferred to Hybond $\mathrm{N}$ plus nylon filters (Amersham). The Southern transfers were prehybridized, hybridized with radiolabeled inserts, washed, and stripped of probe prior to rehybridization, according to the manufacturer's recommendations. Probes were radioactively labeled with $\left[\alpha^{32} \mathrm{P}\right] \mathrm{dCTP}$ by the random primer procedure (Feinberg and Vogelstein, 1984). The hybridized filters were exposed to X-ray film with an intensifying screen at $-70^{\circ} \mathrm{C}$ for $3-7$ days.

Analysis of radiation hybrid data using the method of moments. We analyzed the $\mathrm{RH}$ data using the method of moments, as previously described (Cox et al., 1990). In the $N$-locus case, the likelihood of the $\mathrm{RH}$ data is a function of $N-1$ breakage probabilities between adjacent loci, and one or more retention probabilities. The general model allows all $N(N+1) / 2$ such retention probabilities to differ (Cox et al., 1990 ). Here we also consider an equal retention probability model, in which all retention probabilities are assumed equal. This model has the advantage of requiring fewer parameters than the general, unequal retention frequency model and is computationally much simpler. Computation of the likelihood for the equal retention model scales linearly with the number of loci $N$, while computation for the unequal retention model scales geometrically with $N$ (Boehnke et al., 1991). Both the equal and the unequal retention models assume that breakage occurs at random positions along the chromosome and that fragments are retained independently. Using the method of moments, we estimate the frequency of breakage between two markers, $A$ and $B$, by the equation

$$
\theta=\left\{\left(\mathrm{A}^{+} \mathrm{B}^{-}\right)+\left(\mathrm{A}^{-} \mathrm{B}^{+}\right)\right\} /\left\{(T)\left[R_{\mathrm{A}}+R_{\mathrm{B}}-(2)\left(R_{\mathrm{A}}\right)\left(R_{\mathrm{B}}\right)\right]\right\},
$$

where $\left(A^{+} B^{-}\right)$is the observed number of hybrid clones retaining marker $A$ but not marker $B,\left(A^{-} B^{+}\right)$is the observed number of hybrid clones retaining marker $\mathrm{B}$ but not marker $\mathrm{A}, T$ is the total number of hybrids analyzed for both markers $\mathrm{A}$ and $\mathrm{B}, R_{\mathrm{A}}$ is the fraction of all hybrids analyzed for marker $\mathrm{A}$ that retain marker $\mathrm{A}$, and $R_{\mathrm{B}}$ is the fraction of all hybrids analyzed for marker $B$ that retain marker $B$. For the equal retention model, the single retention frequency $R$ is calculated as 


$$
R=\sum_{M=1}^{N} R_{M} / \sum_{M=1}^{N} T_{M}
$$

where $R_{M}$ is defined as the number of hybrids that retain marker $\mathrm{M}$, $T_{M}$ is defined as the total number of hybrids scored for marker $M$, and $N$ is defined as the total number of markers. The mapping function, $D$ $=-\ln (1-\theta)$, is used to estimate $D$, the distance between two markers. $D$ is expressed in centirays. It is important to include information about X-ray dose when describing the centiray distance between two markers, since the frequency of breakage, and thus $D$, depends on the amount of radiation used to generate the radiation hybrids. A distance of $1 \mathrm{cR}_{8000}$ between two markers corresponds to a $1 \%$ frequency of breakage between the markers after exposure to 8000 rads of $X$ rays.

The lod score for a marker pair is defined as

$$
\operatorname{lod}(\theta)=\log [L(\theta) / L(\theta=1)]
$$

where $L(\theta)$ is the likelihood of obtaining the observed data for a given pair of markers and $L(\theta=1)$ is the likelihood assuming that the two markers are not linked; that is, $\theta=1$. This lod score can be used to identify marker pairs that are significantly linked, in a manner analogous to meiotic mapping (Cox et al., 1990).

In principle, we can use the method of moments to determine the order of markers with the highest overall likelihood given the data. However, for maps consisting of more than four loci, it is impractical to use the unequal retention model and the method of moments to calculate the likelihood for even a single order including all loci (Cox et al., 1990). In contrast, using the equal retention model and the method of moments and assuming that all hybrids are scored for all markers (i.e., no missing data), the overall likelihood for a particular order of many loci can be easily determined by summing the individual two-point likelihoods calculated using adjacent loci. Unfortunately, our chromosome 22 data set has missing data, so we cannot use this approach to determine the overall likelihood of a particular order of many loci. Therefore, we have used the method of moments considering groups of four loci at a time to construct a "framework map" of loci ordered at odds of 1000 to 1 (Cox et al., 1990). In contrast to the maximum likelihood analysis described below, this method includes only those hybrids that have been scored for all four markers in each group, and thus does not include incomplete data. For a given set of four markers, each of the 12 possible orders with likelihoods greater than one thousandth of the most likely order for these four markers is used to construct the map. Such orders for different groups of four markers are used to build a consistent map that includes as many markers as possible. To identify those groups of four markers most useful for constructing the framework map, we first used two-point distances to build a map including all markers, such that the distance between adjacent markers is minimized (Cox et al., 1990). This map is used to select groups of four markers that are considered initially in the construction of the framework map.

Nonframework markers are positioned on the framework map as follows. A nonframework locus is placed sequentially in each of the intervals defined by a set of three framework markers, and the likelihood for each of these locus orders is determined. Those orders with likelihoods greater than one thousandth of the most likely order for the set of four markers represent possible locations for the nonframework locus on the framework map. Likelihood ratios are used to determine the relative odds that a nonframework locus maps within one framework map interval versus another.

Analysis of radiation hybrid data using a maximum likelihood approach. In addition to the method of moments described above, we analyzed the data using the equal retention model and a multipoint maximum likelihood method (Boehnke et al., 1991). Unlike the method of moments, this maximum likelihood method makes use of data on all loci simultaneously, including information on partially typed hybrids. For a given locus order, breakage and retention probabilities are estimated by those values that maximize the likelihood for the RH mapping data. Orders can be compared by their maximum likelihoods, the order with the largest maximum likelihood being best supported by the data.

Since it is not practical to consider explicitly all possible locus orders, we used a stepwise locus-ordering algorithm to identify the most likely locus order (Boehnke et al., 1991). This algorithm builds locus orders by adding one locus at a time. At each stage, it keeps under consideration those partial locus orders no more than $K$ times less likely than the current best partial locus order. Analogous methods are often employed in constructing genetic linkage maps (Barker et al. 1987). We carried out stepwise locus ordering for the equal retention model for the 16 distinguishable loci with $K=10^{8}$.

Stepwise locus ordering results in a list of the locus orders with the largest maximum likelihoods. The comprehensive map is defined as the order from this list with the highest maximum likelihood. A framework map is constructed using orders from this list that have maximum likelihoods no less than one thousandth that of the comprehensive map. We define framework loci as a set of loci whose positions are consistent relative to one another among these orders. As there is no simple algorithm for constructing the largest set of framework loci, this is done by eye. The remaining loci are then considered one at a time to see if any can be added with 1000:1 support to a specific position on the map. Nonframework markers are positioned on the framework map as described above. Each locus is placed sequentially in each of the map intervals defined by the framework markers, and the maximum likelihood for each of these locus orders is determined. Those orders with likelihoods greater than one thousandth of the most likely order represent possible locations for the nonframework locus on the framework map. Likelihood ratios are used to determine the relative odds that a nonframework locus maps within one possible framework interval versus another.

\section{RESULTS}

\section{Radiation Hybrid Data}

To construct an RH map of the NF2 region on human chromosome 22, we isolated DNA from 85 independent radiation hybrids and used Southern blot analysis to determine the presence or absence of 18 human chromosome 22-specific loci in each DNA sample (see Materials and Methods). Although in a few cases the human probes cross-hybridized with hamster DNA, the humanspecific bands could always be distinguished from the hamster bands on the basis of size. The retention frequency of the individual human loci in the radiation hybrids, defined as the fraction of hybrids scored for a locus that retain that locus, ranged from 17 to $42 \%$ (Table 1 ). The segregation patterns observed for all possible pairs of loci in the radiation hybrids are shown in Table 2.

\section{Analysis of Radiation Hybrid Data Using the Method of Moments}

We initially compared the equal and the unequal retention models using the method of moments to estimate the frequency of breakage, $\theta$, and to calculate the lod score for each pair of markers. The distance between two markers, $D$, is expressed in $\mathrm{cR}_{8000}$ (see Materials and Methods). As shown in Table 2, the estimates of distance and lod score are very similar using both the equal and the unequal retention model, despite the fact that the retention frequency is not the same for all of the markers in this data set. Three of the markers, D22S41, D22S42, and D22S46, co-segregated in all of the radiation hybrids, with no evidence of breakage between them 
TABLE 1

Retention Frequencies

\begin{tabular}{lcc}
\hline Locus & No. of hybrids scored & Retention frequency \\
\hline D22S36 & 80 & 0.24 \\
BCRL2 & 71 & 0.42 \\
BCR & 71 & 0.34 \\
D22S1 & 83 & 0.30 \\
D22S33 & 70 & 0.39 \\
D22S41 & 84 & 0.32 \\
D22S42 & 84 & 0.31 \\
D22S46 & 85 & 0.32 \\
D22S56 & 85 & 0.27 \\
LIF & 84 & 0.18 \\
D22S37 & 85 & 0.21 \\
D22S15 & 83 & 0.17 \\
D22S44 & 83 & 0.20 \\
D22S47 & 84 & 0.18 \\
D22S28 & 82 & 0.17 \\
D22S48 & 85 & 0.19 \\
MB & 84 & 0.17 \\
PDGFB & 85 & 0.20 \\
\hline
\end{tabular}

Note. The human chromosome 22 loci scored in the radiation hybrids, the total number of hybrids scored for each locus, and the proportion of hybrids scored for each locus that retain that locus (Retention frequency) are listed.

(Table 2). Therefore, we used only one of these three loci, D22S41, in subsequent analyses. Since it was impractical to calculate the overall likelihood for even a single order of the 16 distinguishable loci under either the unequal retention model or the equal retention model using the method of moments, we constructed a framework map of loci ordered with odds of 1000:1 by considering groups of four markers at a time (see Materials and Methods). As a first step in the construction of this framework map, we used a trial and error process and two-point distance information from Table 2 to construct a map that includes the entire set of 16 markers in an order such that the sum of the distances between adjacent markers is minimized. Under the equal retention model, this map consists of the marker order D22S36-BCR2L-BCR-D22S1-D22S33-D22S41D22S56-LIF-D22S37-D22S44-D22S15-D22S28D22S47-D22S48-MB-PDGFB, spanning a distance of $307 \mathrm{cR}_{8000}$. Under the unequal retention model, the map spans a distance of $301 \mathrm{cR}_{8000}$ with the same order as above, except that the loci D22S33 and D22S1 are inverted. These maps were used to select groups of markers for four-point likelihood calculations. Under the equal retention model, the likelihood for the order BCR2L-BCR-D22S1-D22S56 is more than 1000 times greater than the likelihood of any of the other 11 possible orders of these four markers (Table 3 ). Similarly, the likelihoods of the orders BCR-D22S1-D22S56D22S37,D22S1-D22S56-D22S37-D22S15 and D22S56D22S37-D22S15-D22S28 are more than 1000 times the likelihood of each alternative order, respectively (Table 3 ). Taken together, this set of four four-point orders is consistent with the unique framework order BCR2LBCR-D22S1-D22S56-D22S37-D22S15-D22S28. Simi- lar analyses place PDGFB distal to D22S28 at the opposite end of the map from BCR2L (data not shown). Using the approach described under Materials and Methods, each of the remaining 8 nonframework loci can be localized to a region of the framework map consisting of two adjoining intervals with greater than 1000:1 odds (Fig. 1A). Similar analyses assuming an unequal retention frequency model result in a framework map identical to that described above, and relative likelihoods for the position of nonframework markers that are very similar to those obtained using the equal retention frequency model (data not shown).

\section{Maximum Likelihood Multipoint Analysis of the Radiation Hybrid Data}

As shown above, data analysis using the method of moments provides a single framework map of 8 markers ordered at an odds of 1000:1 employing either the equal retention model or the unequal retention model. However, given the missing data in our data set, it is not practical to use the method of moments to calculate overall likelihoods for maps including all 16 distinguishable markers (see Materials and Methods). Furthermore, since each four-point analysis using the method of moments includes only those hybrids scored for all 4 markers, this method does not include all of the available data, which reduces the power of the analysis. In light of these considerations, we analyzed the data using a maximum likelihood approach, which provides overall likelihoods for maps of the 16 distinguishable markers and incorporates all of the data (see Materials and Methods). We began the maximum likelihood multipoint analysis by carrying out stepwise locus ordering. Table 4 presents the 36 locus orders with maximum likelihoods no more than 1000 times less than that of the best locus order under the equal retention probability model. The most likely comprehensive map spans a distance of $302 \mathrm{cR}_{8000}$ (Fig. 1B). The framework map constructed using the maximum likelihood approach (see Materials and Methods) is identical to that obtained using the method of moments, despite the fact that the method of moments analysis does not incorporate all the data. In addition, the relative likelihoods for the positions of nonframework loci are very similar, although not identical, using the two different methods of analysis (Figs. 1A and 1C).

\section{DISCUSSION}

We have constructed an RH map of human chromosome 22 with 18 22q11.1-22q13.1 markers, 16 of which are distinguishable by $\mathrm{X}$-ray breakage in radiation hybrids. Eight of these markers are uniquely ordered on a framework map with greater than 1000:1 odds, while the remaining nonframework markers are all localized to regions consisting of two adjoining intervals on the framework map with greater than 1000:1 odds. On the basis of 
TABLE 2

Segregration Patterns

\begin{tabular}{|c|c|c|c|c|c|c|c|c|c|c|c|c|}
\hline \multicolumn{2}{|c|}{ MARKERS } & \multirow{2}{*}{$\frac{\# \text { OF }}{++}$} & \multicolumn{2}{|c|}{ CLONES } & \multicolumn{2}{|c|}{ OBSERVED } & \multicolumn{3}{|c|}{ UNEQUAL RETENTION } & \multicolumn{3}{|c|}{ EQUAL RETENTION } \\
\hline A & $\mathrm{B}$ & & +- & -+ & -- & TOT & LOD & $\theta$ & $c R_{8000}$ & LOD & $\theta$ & $c R_{8000}$ \\
\hline D22S36 & $\mathrm{BCR} 2 \mathrm{~L}$ & 19 & 0 & 6 & 41 & 66 & 10.60 & 0.20 & 22 & 10.09 & 0.24 & 28 \\
\hline D22536 & $\mathrm{BCR}$ & 13 & 6 & 8 & 40 & 67 & 3.73 & 0.50 & 70 & 3.61 & 0.56 & 81 \\
\hline D22 2536 & $\mathrm{D} 22 \mathrm{~S} 1$ & 9 & 10 & 11 & 48 & 78 & 1.36 & 0.68 & 114 & 1.25 & 0.72 & 126 \\
\hline D22S36 & D22 533 & 10 & 5 & 12 & 38 & 65 & 2.07 & 0.59 & 90 & 1.73 & 0.70 & 119 \\
\hline $\mathrm{D} 22 \mathrm{~S} 36$ & $\mathrm{D} 22 \mathrm{~S} 41$ & 10 & 9 & 12 & 48 & 79 & 1.68 & 0.65 & 106 & 1.52 & 0.71 & 123 \\
\hline D22S36 & D22S46 & 10 & 9 & 12 & 49 & 80 & 1.73 & 0.65 & 105 & 1.56 & 0.70 & 120 \\
\hline D22S36 & D22S42 & 9 & 9 & 12 & 49 & 79 & 1.47 & 0.66 & 109 & 1.29 & 0.71 & 123 \\
\hline D22S36 & D22S56 & 10 & 9 & 9 & 52 & 80 & 2.32 & 0.59 & 90 & 2.26 & 0.60 & 91 \\
\hline D22S36 & LIF & 8 & 11 & 4 & 56 & 79 & 2.41 & 0.57 & 85 & 2.43 & 0.51 & 70 \\
\hline D22S36 & D22 537 & 10 & 9 & 5 & 56 & 80 & 3.47 & 0.50 & 70 & 3.50 & 0.47 & 63 \\
\hline D22S36 & $\mathrm{D} 22 \mathrm{S4} 4$ & 8 & 11 & 7 & 52 & 78 & 1.59 & 0.67 & 111 & 1.60 & 0.61 & 95 \\
\hline $\mathrm{D} 22536$ & D22S15 & 9 & 10 & 3 & 56 & 78 & 3.37 & 0.51 & 72 & 3.39 & 0.44 & 59 \\
\hline $\mathrm{D} 22 \mathrm{S3} 6$ & $\mathrm{D} 22528$ & 7 & 12 & 5 & 54 & 78 & 1.54 & 0.67 & 110 & 1.53 & 0.58 & 87 \\
\hline D22S36 & D22S47 & 6 & 13 & 6 & 54 & 79 & 0.93 & 0.73 & 129 & 0.89 & 0.64 & 102 \\
\hline D22S36 & D22S48 & 6 & 13 & 7 & 54 & 80 & 0.80 & 0.74 & 136 & 0.76 & 0.67 & 109 \\
\hline D22S36 & MB & 6 & 13 & 5 & 55 & 79 & 1.10 & 0.70 & 121 & 1.07 & 0.61 & 93 \\
\hline D22536 & PDGFB & 9 & 10 & 6 & 55 & 80 & 2.49 & 0.58 & 88 & 2.51 & 0.53 & 76 \\
\hline BCR2L & $\mathrm{BCR}$ & 18 & 9 & 4 & 36 & 67 & 5.21 & 0.41 & 53 & 5.60 & 0.52 & 73 \\
\hline BCR2L & $\mathrm{D} 22 \mathrm{~S} 1$ & 17 & 13 & 5 & 35 & 70 & 3.33 & 0.55 & 79 & 3.47 & 0.68 & 115 \\
\hline BCR2L & $\mathrm{D} 22 \mathrm{S3} 3$ & 18 & 7 & 7 & 29 & 61 & 3.81 & 0.48 & 65 & 4.58 & 0.61 & 94 \\
\hline BCR2L & D22S41 & 18 & 12 & 6 & 35 & 71 & 3.50 & 0.54 & 77 & 3.80 & 0.67 & 112 \\
\hline BCR2L & D22S4 6 & 18 & 12 & 6 & 35 & 71 & 3.52 & 0.54 & 77 & 3.80 & 0.67 & 112 \\
\hline BCR2I & $\mathrm{D} 22 \mathrm{~S} 42$ & 17 & 12 & 6 & 35 & 70 & 3.29 & 0.55 & 79 & 3.47 & 0.68 & 115 \\
\hline BCR2L & $\mathrm{D} 22 \mathrm{~S} 56$ & 16 & 14 & 5 & 36 & 71 & 3.07 & 0.58 & 86 & 2.95 & 0.71 & 125 \\
\hline BCR2L & LIF & 12 & 18 & 2 & 39 & 71 & 2.62 & 0.63 & 98 & 1.77 & 0.75 & 139 \\
\hline BCR2L & $\mathrm{D} 22 \mathrm{~S} 37$ & 13 & 17 & 3 & 38 & 71 & 2.54 & 0.62 & 96 & 1.98 & 0.75 & 139 \\
\hline BCR2L & $\mathrm{D} 22 \mathrm{~S} 44$ & 10 & 20 & 4 & 37 & 71 & 1.07 & 0.74 & 136 & 0.57 & 0.90 & 230 \\
\hline BCR2L & $\mathrm{D} 22 \mathrm{~S} 15$ & 11 & 19 & 2 & 38 & 70 & 2.14 & 0.67 & 110 & 1.28 & 0.80 & 160 \\
\hline BCR2I & D22 528 & 9 & 19 & 3 & 38 & 69 & 1.35 & 0.71 & 124 & 0.71 & 0.85 & 189 \\
\hline BCR2I & D22S47 & 10 & 20 & 3 & 38 & 71 & 1.42 & 0.72 & 127 & 0.76 & 0.86 & 198 \\
\hline BCR2L & $\mathrm{D} 22 \mathrm{~S} 48$ & 10 & 20 & 4 & 37 & 71 & 1.16 & 0.75 & 138 & 0.57 & 0.90 & 230 \\
\hline BCR2L & $\mathrm{MB}$ & 9 & 21 & 3 & 37 & 70 & 1.06 & 0.76 & 145 & 0.42 & 0.91 & 244 \\
\hline BCR2L & PDGFB & 11 & 19 & 3 & 38 & 71 & 1.68 & 0.68 & 115 & 1.11 & 0.82 & 174 \\
\hline $\mathrm{BCR}$ & $\mathrm{D} 22 \mathrm{~S} 1$ & 18 & 5 & 4 & 43 & 70 & 7.77 & 0.30 & 35 & 8.02 & 0.34 & 42 \\
\hline $\mathrm{BCR}$ & $\mathrm{D} 22 \mathrm{S3} 3$ & 19 & 3 & 5 & 32 & 59 & 7.20 & 0.29 & 35 & 7.97 & 0.36 & 45 \\
\hline$B C R$ & $D 22541$ & 19 & 5 & 5 & 42 & 71 & 7.49 & 0.32 & 38 & 7.90 & 0.37 & 47 \\
\hline $\mathrm{BCR}$ & D22S46 & 19 & 5 & 5 & 42 & 71 & 7.50 & 0.32 & 38 & 7.90 & 0.37 & 47 \\
\hline $\mathrm{BCR}$ & $\mathrm{D} 22 \mathrm{S4} 2$ & 18 & 5 & 5 & 42 & 70 & 7.12 & 0.33 & 39 & 7.43 & 0.38 & 48 \\
\hline $\mathrm{BCR}$ & D22S56 & 15 & 9 & 5 & 42 & 71 & 4.48 & 0.46 & 62 & 4.53 & 0.52 & 74 \\
\hline $\mathrm{BCR}$ & $\mathrm{LIF}$ & 9 & 15 & 5 & 42 & 71 & 1.48 & 0.71 & 124 & 1.15 & 0.75 & 139 \\
\hline $\mathrm{BCR}$ & D22S37 & 11 & 13 & 5 & 42 & 71 & 2.28 & 0.62 & 98 & 2.05 & 0.67 & 112 \\
\hline $\mathrm{BCR}$ & $\mathrm{D} 22 \mathrm{S4} 4$ & 9 & 14 & 5 & 42 & 70 & 1.52 & 0.67 & 111 & 1.30 & 0.72 & 128 \\
\hline $\mathrm{BCR}$ & D22S15 & 9 & 15 & 4 & 42 & 70 & 1.71 & 0.69 & 118 & 1.30 & 0.72 & 128 \\
\hline $\mathrm{BCR}$ & $\mathrm{D} 22528$ & 8 & 16 & 5 & 42 & 71 & 1.09 & 0.75 & 139 & 0.78 & 0.79 & 155 \\
\hline $\mathrm{BCR}$ & $\mathrm{D} 22547$ & 7 & 17 & 5 & 42 & 71 & 0.69 & 0.78 & 153 & 0.48 & 0.82 & 174 \\
\hline $\mathrm{BCR}$ & D22 248 & 9 & 15 & 4 & 43 & 71 & 1.63 & 0.67 & 111 & 1.34 & 0.71 & 125 \\
\hline$B C R$ & $\mathrm{MB}$ & 9 & 15 & 3 & 43 & 70 & 1.94 & 0.66 & 107 & 1. 51 & 0.68 & 115 \\
\hline $\mathrm{BCR}$ & PDGFB & 10 & 14 & 4 & 43 & 71 & 2.07 & 0.63 & 99 & 1.80 & 0.67 & 112 \\
\hline D22S1 & D22 233 & 24 & 0 & 2 & 43 & 69 & 16.00 & 0.06 & 7 & 16.60 & 0.08 & 8 \\
\hline D22S1 & D22S41 & 24 & 1 & 1 & 56 & 82 & 17.91 & 0.06 & 6 & 18.15 & 0.06 & 7 \\
\hline D22S1 & D22S46 & 24 & 1 & 1 & 57 & 83 & 18.06 & 0.06 & 6 & 18.26 & 0.06 & 7 \\
\hline D2251 & D22S42 & 23 & 1 & 1 & 57 & 82 & 17.56 & 0.06 & 6 & 17.68 & 0.06 & 7 \\
\hline D22S1 & D22S56 & 20 & 5 & 1 & 57 & 83 & 12.28 & 0.18 & 19 & 12.29 & 0.19 & 21 \\
\hline D2 251 & LIF & 14 & 11 & 1 & 57 & 83 & 6.46 & 0.39 & 49 & 6.00 & 0.38 & 49 \\
\hline D22S1 & $\mathrm{D} 22 \mathrm{~S} 37$ & 15 & 10 & 2 & 56 & 83 & 6.61 & 0.38 & 47 & 6.37 & 0.38 & 49 \\
\hline D22S1 & $\mathrm{D} 22 \mathrm{~S} 44$ & 13 & 11 & 3 & 54 & 81 & 4.84 & 0.45 & 60 & 4.60 & 0.46 & 62 \\
\hline $\mathrm{D} 22 \mathrm{S1}$ & D22S15 & 11 & 13 & 3 & 55 & 82 & 3.66 & 0.53 & 75 & 3.26 & 0.52 & 73 \\
\hline $\mathrm{D} 22 \mathrm{S1}$ & $\mathrm{D} 22 \mathrm{~S} 28$ & 11 & 12 & 2 & 55 & 80 & 4.24 & 0.47 & 64 & 3.84 & 0.47 & 63 \\
\hline $\mathrm{D} 22 \mathrm{S1}$ & D22 547 & 12 & 13 & 2 & 55 & 82 & 4.31 & 0.49 & 68 & 3.94 & 0.49 & 67 \\
\hline D2251 & $\mathrm{D} 22548$ & 14 & 11 & 1 & 57 & 83 & 6.38 & 0.38 & 49 & 6.00 & 0.38 & 49 \\
\hline D22S1 & MB & 12 & 12 & 1 & 57 & 82 & 5.21 & 0.43 & 56 & 4.73 & 0.42 & 55 \\
\hline D22S1 & PDGFB & 12 & 13 & 4 & 54 & 83 & 3.54 & 0.54 & 77 & 3.32 & 0.55 & 79 \\
\hline D22S33 & $\mathrm{D} 22541$ & 25 & 2 & 0 & 42 & 69 & 16.15 & 0.06 & 7 & 17.06 & 0.08 & 8 \\
\hline D22S33 & $\mathrm{D} 22 \mathrm{~S} 46$ & 25 & 2 & 0 & 43 & 70 & 16.34 & 0.06 & 6 & 17.18 & 0.08 & 8 \\
\hline
\end{tabular}


TABLE 2-Continued

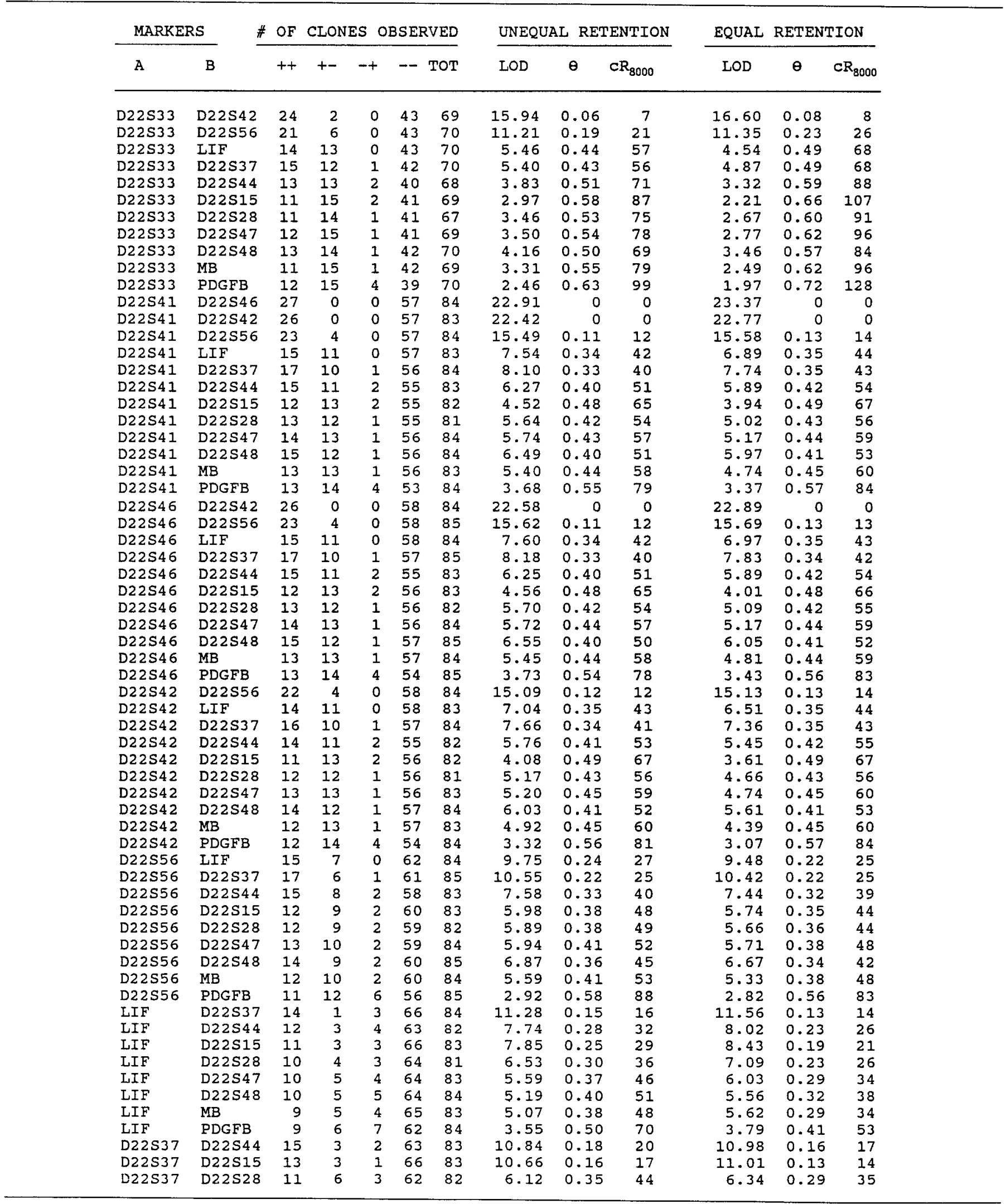


TABLE 2-Continued

\begin{tabular}{|c|c|c|c|c|c|c|c|c|c|c|c|c|}
\hline \multicolumn{2}{|c|}{ MARKERS } & \multirow{2}{*}{$\frac{O F}{++}$} & \multicolumn{2}{|c|}{ CLONES } & \multicolumn{2}{|c|}{ OBSERVED } & \multicolumn{3}{|c|}{ UNEQUAL RETENTION } & \multirow{2}{*}{$\frac{\text { EQUAL }}{\text { LOD }}$} & \multicolumn{2}{|c|}{ RETENTION } \\
\hline A & B & & +- & -+ & -- & TOT & LOD & $\theta$ & $C R_{8000}$ & & $\theta$ & $c R_{8000}$ \\
\hline D22S37 & D22S47 & 11 & 7 & 4 & 62 & 84 & 5.27 & 0.42 & 54 & 5.44 & 0.35 & 43 \\
\hline D22537 & D22 2548 & 12 & 6 & 4 & 63 & 85 & 6.26 & 0.37 & 46 & 6.43 & 0.31 & 38 \\
\hline D22S37 & $\mathrm{MB}$ & 11 & 6 & 3 & 64 & 84 & 6.26 & 0.35 & 43 & 6.52 & 0.29 & 34 \\
\hline D22S37 & PDGFB & 10 & 8 & 7 & 60 & 85 & 3.36 & 0.54 & 78 & 3.46 & 0.47 & 63 \\
\hline D22S44 & D22S15 & 13 & 2 & 1 & 65 & 81 & 11.4 & 0.12 & 13 & 11.80 & 0.10 & 10 \\
\hline D22S44 & D22S28 & 12 & 4 & 2 & 62 & 80 & 8.28 & 0.25 & 28 & 8.56 & 0.20 & 22 \\
\hline D22S4 4 & D22S47 & 12 & 5 & 3 & 63 & 83 & 7.21 & 0.31 & 37 & 7.45 & 0.26 & 30 \\
\hline D22S44 & D22S48 & 13 & 4 & 3 & 63 & 83 & 8.33 & 0.27 & 31 & 8.54 & 0.22 & 25 \\
\hline D22S44 & MB & 12 & 4 & 2 & 64 & 82 & 8.43 & 0.24 & 28 & 8.76 & 0.19 & 22 \\
\hline D22S44 & PDGFB & 11 & 6 & 5 & 61 & 83 & 5.18 & 0.41 & 53 & 5.36 & 0.35 & 44 \\
\hline D22S15 & D2 2S28 & 10 & 3 & 2 & 65 & 80 & 7.74 & 0.22 & 25 & 8.48 & 0.17 & 18 \\
\hline D22S15 & D22547 & 10 & 4 & 3 & 65 & 82 & 6.60 & 0.30 & 35 & 7.18 & 0.23 & 26 \\
\hline D22S15 & D22548 & 10 & 4 & 4 & 65 & 83 & 6.13 & 0.33 & 40 & 6.63 & 0.26 & 30 \\
\hline D22S15 & MB & 10 & 4 & 3 & 66 & 83 & 6.63 & 0.30 & 36 & 7.28 & 0.22 & 25 \\
\hline D22S15 & PDGFB & 9 & 5 & 7 & 62 & 83 & 3.87 & 0.48 & 65 & 4.14 & 0.38 & 49 \\
\hline D22S28 & D22S47 & 13 & 1 & 0 & 67 & 81 & 13.66 & 0.04 & 4 & 14.34 & 0.03 & 3 \\
\hline D22528 & $D 22548$ & 13 & 1 & 1 & 67 & 82 & 12.48 & 0.08 & 9 & 13.07 & 0.06 & 7 \\
\hline D22S28 & $\mathrm{MB}$ & 12 & 1 & 1 & 67 & 81 & 11.72 & 0.09 & 9 & 12.50 & 0.07 & 7 \\
\hline D22S28 & PDGFB & 10 & 4 & 6 & 62 & 82 & 5.11 & 0.40 & 52 & 5.40 & 0.32 & 39 \\
\hline D22S47 & $\mathrm{D} 22548$ & 14 & 1 & 2 & 67 & 84 & 12.18 & 0.12 & 13 & 12.59 & 0.10 & 10 \\
\hline D22S47 & $\mathrm{MB}$ & 12 & 2 & 2 & 67 & 83 & 9.94 & 0.17 & 18 & 10.56 & 0.13 & 14 \\
\hline D22S47 & PDGFB & 10 & 5 & 7 & 62 & 84 & 4.37 & 0.47 & 63 & 4.59 & 0.38 & 48 \\
\hline D22S48 & MB & 14 & 1 & 0 & 69 & 84 & 14.58 & 0.04 & 4 & 15.18 & 0.03 & 3 \\
\hline D22S48 & PDGFB & 11 & 5 & 6 & 63 & 85 & 5.30 & 0.41 & 53 & 5.52 & 0.34 & 42 \\
\hline $\mathrm{MB}$ & PDGFB & 11 & 3 & 6 & 64 & 84 & 6.22 & 0.36 & 44 & 6.52 & 0.29 & 34 \\
\hline
\end{tabular}

Note. All pairwise combinations of the 18 chromosome 22 DNA markers used to generate the radiation hybrid map are listed. For each marker pair, the number of radiation hybrids containing both markers $A$ and $B(++)$, containing marker $A$ but not $B(+-)$, containing marker $B$ but not A $(-+)$, and containing neither marker A nor B (--), as well as the total number of hybrids analyzed for both markers (TOT), are listed. The lod scores (LOD), breakage probability estimates $(\theta)$, and distance estimates $\left(\mathrm{cR}_{8000}\right)$ in $\mathrm{RH}$ map units were calculated using the method of moments with either the unequal retention probability model (Unequal retention) or the equal retention probability model (Equal retention) (see Materials and Methods).

our RH map, the NF2 region of chromosome 22, between D22S1 and D22S28, is the most likely location for 9 of the 18 markers studied: D22S33, D22S41, D22S42, D22S46, D22S56, LIF, D22S37, D22S44, and D22S15.

We have used two different statistical estimation procedures to analyze our data: the method of moments and a maximum likelihood approach. The method of moments provides a simple, rapid approach for constructing RH maps, particularly in those cases where an equal retention frequency model can be employed. In such cases, an overall likelihood for a particular order of markers can be obtained by simply summing the lod scores for adjacent loci (Richard et al., 1991). However, it is important to recognize that summing lod scores for adjacent locus pairs to obtain the multipoint maximum lod score requires that every locus be typed in every hybrid. In cases where there are substantial missing data, as is the case for the data set analyzed here, such an approach should not be employed. In such situations, one can still use the method of moments to calculate likelihoods, considering four loci at a time. However, in such cases, the approach no longer provides a practical means for determining the overall likelihood of a given order of more than four markers, and does not incorporate information from partially typed hybrids in the analysis. In contrast, the maximum likelihood approach does incorporate information from partially typed hybrids in the calculation of overall likelihoods, making it

TABLE 3

Four-Point Analysis Using the Method of Moments

\begin{tabular}{llll}
\hline \multicolumn{1}{c}{ Most likely order } & \multicolumn{1}{c}{ Second most likely order } \\
\hline BCR2L-BCR-D22S1-D22S56 & BCR-D22S1-D22S56-BCR2L & Odds \\
BCR-D22S1-D22S56-D22S37 & BCR-D22S1-D22S37-D22S56 & $9.7 \times 10^{3}$ \\
D22S1-D22S56-D22S37-D22S15 & D22S1-D22S56-D22S15-D22S37 & $7.0 \times 10^{5}$ \\
D22S56-D22S37-D22S15-D22S28 & D22S15-D22S37-D22S56-D22S28 & $5.6 \times 10^{3}$ & \\
\hline
\end{tabular}

Note. An equal retention probability model and the method of moments were used to estimate the likelihoods of the 12 possible orders for each set of 4 markers listed above. The most likely order and the second most likely order, as well as the odds favoring the most likely order over the second most likely order, are listed for each of the 4 sets of markers. The odds were determined by likelihood ratios (see Materials and Methods). 
Method of Moments

A. Framework Map

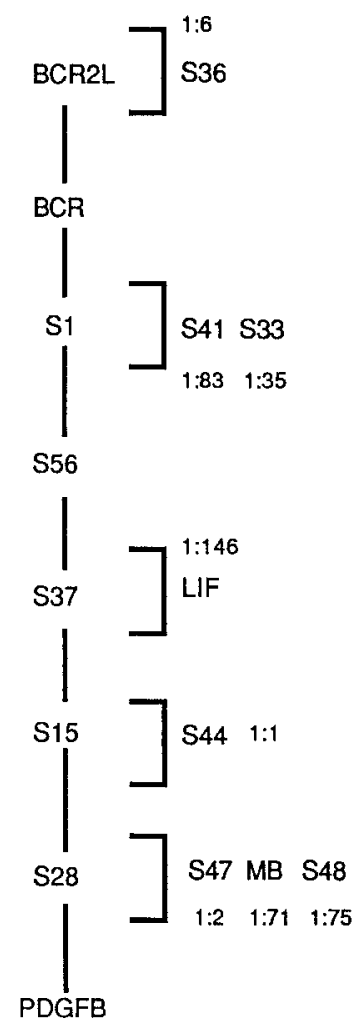

Maximum Likelihood Method

B. Comprehensive Map

C. Framework Map

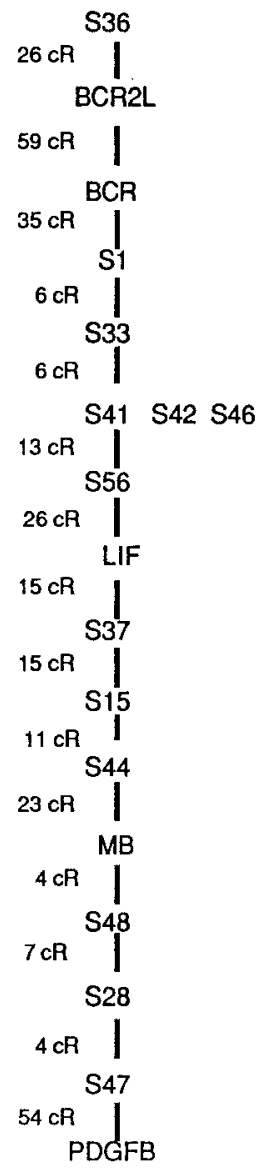

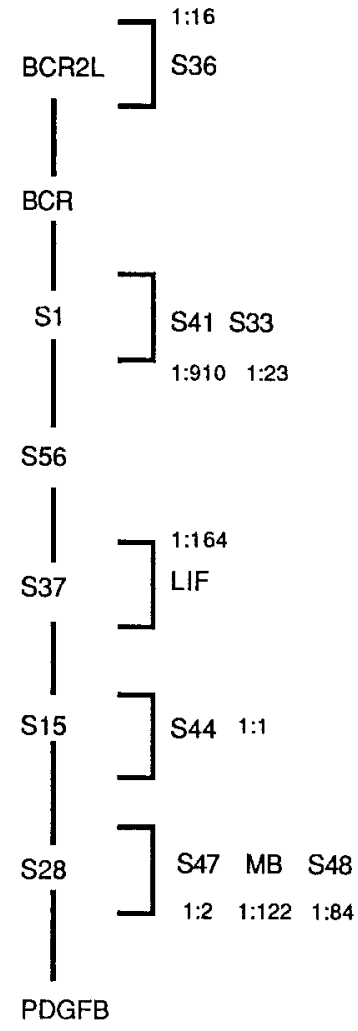

PDGFB

FIG. 1. (A and C) Framework RH maps constructed assuming an equal retention frequency model using the method of moments analysis and the maximum likelihood analysis, respectively. Brackets mark the regions in which loci not in the framework map cannot be excluded based on relative maximum likelihoods of 1000:1. Numbers adjacent to a locus provide relative likelihoods for the two possible positions of that locus; numbers above (below) a locus indicate that the upper (lower) position has the larger maximum likelihood. For example, LIF is 164 times more likely to be located between S56 and S37 than between S37 and S15 on the maximum likelihood framework map. (B) The most likely comprehensive RH map based on the maximum likelihood method. Distances between the markers are indicated in $\mathrm{cR}_{8000}$ to the left of the diagrams. The DNA markers are abbreviated by deleting D22, so that D22S1 $=\mathrm{S} 1$.

possible to compare the likelihoods for different maps and to identify the map that best fits the data. The only disadvantage of the maximum likelihood method is that it is more mathematically complex than the method of moments and requires a sophisticated computer software package. In contrast, the mathematical simplicity of the method of moments makes this approach more attractive for initial interactive data analysis by the experimental scientist.

In the present case, the order of markers on the framework map, as well as the likelihoods for the positions of the nonframework markers on this framework map, obtained with the method of moments is very similar to that obtained with the maximum likelihood approach. The most striking exception is the placement of marker D22S41, which is placed in the interval D22S1-D22S56 versus the interval BCR-D22S1 with odds of 910:1 using maximum likelihood analysis, but with odds of only 83:1 using the method of moments. Although the method of moments and the maximum likelihood analysis give sim- ilar results for this data set, we recommend the maximum likelihood approach in those cases where there are significant missing data.

Recent studies have demonstrated that it is much easier to score for the presence of human DNA markers in radiation hybrids by using PCR-based assays and analyzing ethidium-stained gels than by using Southern blotting procedures (Richard et al., 1991). This change in methodology is likely to produce data sets with many fewer missing data than has been the case to date. Given such data sets with little or no missing data and assuming an equal retention frequency model, the method of moments approach can be expected to give results very similar to those obtained using the computationally more complex maximum likelihood approach. Whether the mathematical simplicity of the method of moments will make it the preferred method of analysis in such cases will require further study.

Irrespective of the statistical estimation procedure employed, analysis of $\mathrm{RH}$ data is significantly less com- 
TABLE 4

Maximum Likelihood Locus Orders for the Chromosome 22 Radiation Hybrid Mapping Data

\begin{tabular}{|c|c|c|c|c|c|c|c|c|c|c|c|c|c|c|c|}
\hline \multirow{2}{*}{$\frac{\text { Rank }}{1}$} & \multirow[b]{2}{*}{ S36 } & \multirow[b]{2}{*}{ BCR2L } & \multirow[b]{2}{*}{$\mathrm{BCR}$} & \multirow[b]{2}{*}{ S1 } & \multirow[b]{2}{*}{$\$ 33$} & \multirow[b]{2}{*}{$S 41$} & \multicolumn{3}{|c|}{ Locus } & \multicolumn{2}{|l|}{ Order } & \multirow[b]{2}{*}{ MB } & \multirow[b]{2}{*}{$\mathrm{S} 28$} & \multirow[b]{2}{*}{ PDGEB } & $\begin{array}{c}\text { Relative } \\
\text { Likelihood }\end{array}$ \\
\hline & & & & & & & S56 & LIF & S37 & S15 & $S 44$ & & & & 1 \\
\hline 2 & $S 36$ & BCR2L & $\mathrm{BCR}$ & $\mathrm{S} 1$ & S33 & $S 41$ & S56 & LIF & 537 & $\mathrm{~S} 15$ & S44 & $\$ 47$ & $S 48$ & PDGFB & 3 \\
\hline 3 & S36 & BCR2L & $\mathrm{BCR}$ & S1 & S33 & S4I & S56 & LIF & S37 & $\$ 44$ & $S 15$ & $\mathrm{~S} 47 \quad \mathrm{~S} 28$ & $\mathrm{~S} 48 \quad \mathrm{MB}$ & PDGFB & 5 \\
\hline 4 & s36 & BCR2L & $\mathrm{BCR}$ & S1 & S33 & $S 41$ & S56 & LIF & 537 & $\mathrm{~S} 15$ & $S 44$ & MB $\quad S 48$ & $\$ 47 \quad \$ 28$ & PDGFB & 6 \\
\hline 5 & s36 & BCR2I & $\mathrm{BCR}$ & s1 & S33 & $S 41$ & S56 & LIF & $S 37$ & $\mathrm{~S} 15$ & S44 & $\$ 28 \quad 547$ & $\mathrm{~S} 48 \quad \mathrm{MB}$ & PDGFB & 8 \\
\hline 6 & S36 & BCR2L & $\mathrm{BCR}$ & $\mathrm{S} 1$ & S33 & 541 & S56 & LIF & S37 & $\$ 44$ & S15 & $\$ 28 \quad \$ 47$ & $\mathrm{~S} 48 \quad \mathrm{MB}$ & PDGF B & 12 \\
\hline 7 & $\mathrm{BCB} 2 \mathrm{I}$ & L $\$ 36$ & $\mathrm{BCR}$ & s1 & S33 & $S 41$ & S56 & LIF & S37 & S15 & S44 & MB $\quad S 48$ & $528 \quad 547$ & PDGFB & 17 \\
\hline 8 & s36 & BCR2L & $\mathrm{BCR}$ & $\$ 33$ & s1 & $S 41$ & S56 & IIF & 537 & S15 & S44 & MB $\quad S 48$ & $S 28 \quad S 47$ & PDGFB & 26 \\
\hline 9 & $\mathrm{BCB} 2 \mathrm{I}$ & L $\$ 36$ & $\mathrm{BCR}$ & $S 1$ & S33 & $S 41$ & S56 & LIF & S37 & S15 & S44 & $\$ 47 \quad \$ 28$ & $S 48 \quad M B$ & PDGFB & 47 \\
\hline 10 & $\mathrm{~s} 36$ & $\mathrm{BCR} 2 \mathrm{~L}$ & $\mathrm{BCR}$ & $\$ 33$ & s1 & $S 41$ & S56 & IIF & 537 & S15 & S44 & $\$ 47 \quad \$ 28$ & $S 48 \quad M B$ & PDGFB & 71 \\
\hline 11 & $\mathrm{BCR} 2 \mathrm{I}$ & I 536 & $\mathrm{BCR}$ & $\mathrm{S} 1$ & s33 & $S 41$ & S56 & LIF & S37 & $\$ 44$ & $\$ 15$ & $\$ 47 \quad \$ 28$ & $548 \quad \mathrm{MB}$ & PDGFB & 84 \\
\hline 12 & $\mathrm{BCR} 2 \mathrm{I}$ & I 536 & $\mathrm{BCR}$ & S1 & s33 & $S 41$ & $S 56$ & LIF & S37 & S15 & $S 44$ & $\mathrm{MB} \quad \mathrm{S} 48$ & $\$ 47 \quad 528$ & PDGFB & 98 \\
\hline 13 & PDGFE & $\underline{\underline{B}} \quad S 36$ & BCR2 & $2 \mathrm{~L} \mathrm{BCR}$ & R S1 & S33 & S41 & $S 56$ & LIF & S37 & S15 & $\mathrm{S} 44 \mathrm{MB}$ & $\mathrm{S} 48 \quad \mathrm{~S} 28$ & $S 47$ & 107 \\
\hline 14 & S36 & BCR2L & $\mathrm{BCR}$ & $\mathrm{S} 1$ & $\mathrm{~S} 33$ & $\mathrm{~S} 41$ & S56 & LIF & S37 & $\$ 44$ & $S 15$ & MB $\quad \$ 48$ & $S 28 \quad S 47$ & PDGFB & 124 \\
\hline 15 & $\mathrm{~S} 36$ & BCR2L & $\mathrm{BCR}$ & $\$ 33$ & s1 & $\mathrm{S} 41$ & S56 & $\mathrm{LIF}$ & 537 & $\$ 44$ & $\$ 15$ & $S 47 \quad S 28$ & S48_ MB & PDGFB & 126 \\
\hline 16 & BCR2I & I $\$ 36$ & $\mathrm{BCR}$ & $\mathrm{S} 1$ & s33 & $\mathbf{S 4 1}$ & S56 & LIF & S37 & S15 & $\mathrm{S} 44$ & $\$ 28 \quad \$ 47$ & S48 MB & PDGFB & 144 \\
\hline 17 & 536 & BCR2L & $\mathrm{BCR}$ & $\$ 33$ & $S 1$ & $S 41$ & S56 & $\mathrm{LIF}$ & $\$ 37$ & $\mathrm{~S} 15$ & $S 44$ & MB $\quad 548$ & $\$ 47 \quad \$ 28$ & PDGFB & 147 \\
\hline 18 & s36 & BCR2L & $\mathrm{BCR}$ & $\mathrm{S} 1$ & s33 & $\mathrm{S} 41$ & S56 & 532 & LIE & $\mathrm{S} 15$ & S4 4 & MB $\quad S 48$ & $\mathrm{~S} 28 \quad \mathrm{~S} 47$ & PDGFB & 159 \\
\hline 19 & 536 & BCR2L & $\mathrm{BCR}$ & $\mathrm{s} 1$ & s33 & $S 41$ & S56 & LIF & S37 & $\mathrm{S} 15$ & $\mathrm{~S} 44$ & $\mathrm{~S} 48 \quad \mathrm{MB}$ & $\mathrm{S} 28 \quad \mathrm{~S} 47$ & PDGFB & 175 \\
\hline 20 & BCR2I & I. $\$ 36$ & $\mathrm{BCR}$ & $\mathrm{SI}$ & S33 & $\mathrm{S} 41$ & S56 & LIF & S37 & $\$ 44$. & $\$ 15$ & $\$ 28 \quad \$ 47$ & S48 MB & PDGFB & 211 \\
\hline 21 & s36 & $\mathrm{BCR} 2 \mathrm{~L}$ & $\mathrm{BCR}$ & 533 & S1 & $S 41$ & S56 & $\operatorname{LIF}$ & 537 & S15 & $\mathrm{S} 44$ & $\$ 28 \quad \$ 47$ & $\mathrm{~S} 48 \quad \mathrm{MB}$ & PDGFB & 216 \\
\hline 22 & s36 & BCR2L & $\mathrm{BCR}$ & S1 & $\$ 41$ & $\$ 33$ & S56 & LIF & S37 & $\mathrm{S} 15$ & $S 44$ & MB $\quad 548$ & S28 & PDGFB & 238 \\
\hline 23 & s36 & BCR2L & $\mathrm{BCR}$ & $\mathrm{s} 1$ & s33 & $S 41$ & S56 & LIF & 537 & S15 & $\mathrm{S} 44$ & $\$ 47 \quad$ S28 & MB $\quad S 48$ & PDGFB & 311 \\
\hline 24 & s36 & BCR2I & $\mathrm{BCR}$ & $\$ 33$ & S1 & $S 41$ & S56 & $\operatorname{LIF}$ & 537 & $\mathbf{S 4 4}$ & $S 15$ & $528 \quad 547$ & $\mathrm{~S} 48 \quad \mathrm{MB}$ & PDGFB & 317 \\
\hline 25 & $\mathrm{BCR} 2 \mathrm{I}$ & I 536 & $\mathrm{BCR}$ & $\$ 33$ & s1 & $S 41$ & S56 & LIF & S37 & S15 & S44 & $\mathrm{MB} \quad \mathrm{S} 48$ & $\mathrm{~S} 28$ & PDGFB & 421 \\
\hline 26 & S36 & BCR2L & $B C R$ & S1 & s33 & $S 41$ & S56 & $\$ 37$ & LIE & S15 & $S 44$ & $\$ 47 \quad \$ 28$ & $\mathrm{~S} 48 \quad \mathrm{MB}$ & PDGFB & 436 \\
\hline 27 & s36 & BCR2L & $\mathrm{BCR}$ & $\mathrm{s} 1$ & s33 & S41 & S56 & $\$ 37$ & IIIF & $\$ 44$ & S15 & $\$ 47 \quad \$ 28$ & $S 48 \quad M B$ & PDGFB & 516 \\
\hline 28 & s36 & BCR2I & $B C R$ & $\mathrm{~s} 1$ & S33 & $\mathrm{S} 41$ & S56 & LIF & S37 & $\$ 44$ & $\$ 15$ & $\$ 47 \quad \$ 28$ & MB $S 48$ & PDGFB & 553 \\
\hline 29 & s36 & BCR2L & $\mathrm{BCR}$ & $\$ 41$ & 533 & S1 & S56 & LIF & S37 & S15 & S44 & MB $\quad 548$ & $\mathrm{~S} 28 \quad \mathrm{~S} 47$ & PDGFB & 618 \\
\hline 30 & S36 & BCR 2L & $B C R$ & $S 41$ & s1 & $\mathrm{S33}$ & S56 & LIF & 537 & S15 & $\mathrm{S} 44$ & MB $\quad S 48$ & $528 \quad 547$ & PDGFB & 649 \\
\hline 31 & $s 36$ & BCR2L & $B C R$ & S1 & $\$ 41$ & $\$ 33$ & $S 56$ & LIF & 537 & S15 & $\$ 44$ & $\$ 47 \quad \$ 28$ & $548 \quad \mathrm{MB}$ & PDGFB & 653 \\
\hline 32 & s36 & BCR2L & BCR & S1 & S33 & $S 41$ & S56 & LIF & 537 & $\$ 44$ & $\$ 15$ & MB $\quad 548$ & $\$ 47 \quad 528$ & PDGFB & 710 \\
\hline 33 & s36 & BCR2L & $B C R$ & S1 & S33 & $S 41$ & S56 & $\mathrm{LIF}$ & 537 & S15 & $S 44$ & PDGFB MB & $\mathrm{S} 48$ & 547 & 890 \\
\hline 34 & 536 & $\mathrm{BCR} 2 \mathrm{~L}$ & $B C R$ & S1 & S33 & $S 41$ & S56 & $\$ 37$ & LIF & S15 & S44 & MB $\quad S 48$ & $\$ 47 \quad \$ 28$ & PDGFB & 908 \\
\hline 35 & S36 & $\mathrm{BCR} 2 \mathrm{~L}$ & $\mathrm{BCR}$ & $\mathrm{S} 1$ & s33 & S41 & S56 & LIF & S37 & s15 & $S 44$ & $\$ 28 \quad \$ 47$ & MB $\quad 548$ & PDGFBB & 912 \\
\hline 36 & s36 & $\mathrm{BCR} 2 \mathrm{~L}$ & $\mathrm{BCR}$ & $\mathrm{s} 1$ & \$33 & S4 1 & S56 & LIF & S37 & $\$ 15$ & 544 & $S 48 \quad \mathrm{MB}$ & $\$ 47 \quad \$ 28$ & PDGFBB & 951 \\
\hline
\end{tabular}

Note. Relative likelihood compares the maximum likelihood for the given locus order to that for the overall maximum likelihood order. Underlines indicate inversions of two or more loci relative to the best locus order; double underlines indicate more complex modifications. The DNA markers are abbreviated by deleting $\mathrm{D} 22$, so that $\mathrm{D} 22 \mathrm{~S} 1=\mathrm{S} 1$. 
plicated if one can use a model of equal marker retention frequency as opposed to a model of unequal marker retention frequency. In certain instances, including the present data set, the equal retention model yields estimates of distance and lod scores that are very similar to estimates obtained using the unequal retention model, even though the observed marker retention is clearly not the same for all markers (see Boehnke et al., 1991). Whether this will be the case for all data sets with unequal marker retention remains to be determined.

Although the maximum likelihood approach identifies a comprehensive map of the 16 distinguishable markers that is most likely, given the data, it should be emphasized that this order of markers is not significantly more likely than a number of other map orders listed in Table 4. We are confident of the order of a set of markers only when the odds of that order are greater than 1000:1 compared to all other orders. Thus, in a practical sense, the framework map is much more useful than the comprehensive map. It is interesting to note that the most likely position of a nonframework locus with respect to flanking framework loci can differ, depending on whether one considers the nonframework locus with respect to only framework markers or with respect to both framework and nonframework markers on the comprehensive map. For example, although $\mathrm{MB}$ is in the D22S15-D22S28 interval on the comprehensive map, it is more likely located in the D22S28-PDFGB interval versus the D22S15-D22S28 interval with odds of 122:1 when considered solely with respect to the framework markers. Independent physical mapping information indicates that MB does indeed map between D22S28 and PDFGB (Delattre et al., 1991). This example illustrates that although the comprehensive map may be the most likely map given the data, it is not always the correct map and should not be considered as such.

The region of chromosome 22 between markers D22S1 and D22S15 is known to be involved in Ewing sarcoma and neuroepithelioma, malignant small round cell tumors often associated with somatic $\mathrm{t}(11: 22)$ (q24; q12)translocations (Budarf et al., 1989). Previously, the Ewing sarcoma translocation breakpoint was mapped on chromosome 22 between flanking markers D22S1, D22S41, D22S46, D22S42, and D22S56 on the proximal side and markers LIF, D22S37, D22S44, D22S15, and D22S28 on the distal side (Budarf et al., 1989; Selleri et al., 1991). Because our framework $\mathrm{RH}$ map orders these markers, we have refined the location of the Ewing sarcoma breakpoint between the proximal marker D22S56 and the distal markers LIF and D22S37, a distance of approximately $30 \mathrm{cR}_{8000}$.

The order of the markers on the framework $\mathrm{RH}$ map is consistent with existing physical and genetic linkage maps of chromosome 22. Somatic cell hybrid panels of chromosome 22 have previously placed the markers used to construct our RH map into four regions (Budarf et al., 1989, 1991). The markers D22S36 and BCR2L have been localized centromeric to the constitutional $t(11 ; 22)$ breakpoint; BCR has been mapped at the chromosome
22 breakpoint observed in chronic myelogenous leukemia (CML); D22S1, D22S33, D22S46, D22S42, and D22S41 lie between the CML and Ewing sarcoma related breakpoints; and LIF, D22S37, D22S44, D22S15, D22S28, D22S47, D22S48, MB, and PDGFB map distal to the Ewing sarcoma breakpoint. Several of the probes that lie distal to the Ewing sarcoma breakpoint have recently been linearly ordered in defined groups of markers using somatic cell hybrids: (D22S15,LIF)(D22S28)-(MB)-(PDGFB) (Delattre et al., 1991). Thus, these data assigning DNA markers to physical locations are consistent with the order of these markers in our $\mathrm{RH}$ framework map. Published genetic linkage maps of chromosome 22 include one by Dumanski et al. (1991), which consists of 40 markers; one by Rouleau et al. (1989), which consists of 16 markers; and one by Julier et al. (1988), which consists of 5 markers. These maps share in common with our RH map 4 markers (BCR, D22S1, MB, and PDGFB), 5 markers (BCR, D22S1, D22S15, D22S28 and PDGFB), and 2 markers (MB and PDGFB), respectively. Our RH framework map is consistent with the order and orientation of the markers shared with these genetic linkage maps. In some instances, the $\mathrm{RH}$ map provides strong support for the order of markers when other methods provide either no support or only weak support for order (i.e., the order of LIF with respect to D22S15). In other situations, another method provides strong support for an order that is only weakly supported by the RH map (i.e., the order of D22S28 with respect to $\mathrm{MB}$ ). These comparisons of the $\mathrm{RH}$ map with the available physical and genetic maps of human chromosome 22 illustrate the power of using complementary methods to obtain high-resolution maps of mammalian chromosomes.

Our RH mapping data can be used to estimate the physical distance of the markers within and flanking the NF2 region. Previous comparisons of $\mathrm{RH}$ map distance with physical distance have not revealed any hot or cold spots of chromosome X-ray breakage distorting the relationship between $\mathrm{RH}$ map units and physical distance and suggest that $1 \mathrm{cR}_{8000}$ corresponds to approximately $50 \mathrm{~kb}$ (Cox et al., 1990; Burmeister et al., 1991). Thus, assuming that $\mathrm{RH}$ mapping closely reflects physical distance, we estimate that the $302 \mathrm{cR}_{8000}$ region spanned by the 16 markers that comprise the maximum likelihood comprehensive map equals a physical distance of approximately $15 \mathrm{Mb}$. Similarly, we estimate that the $126 \mathrm{cR}_{8000}$ region of the map between the flanking markers of the NF2 gene, D22S1 and D22S28, represents approximately $6 \mathrm{Mb}$ or $10 \%$ of the total length of the long arm of chromosome 22.

\section{ACKNOWLEDGMENTS}

We thank E. Shtivelman, D. F. Lowe, D. Mirada, R. White, P. Weller, and J. Gusella for generously providing the probes used in this study; U. Francke and M. Van Keuren, respectively, for the 380-6 and EYEF3A6 cell lines; S. Kim for technical assistance growing the radiation hybrid cell lines; and G. Duyk and H. McDermid for useful discussions and assistance in obtaining materials. R.K.W. is supported 
by a National Neurofibromatosis Foundation fellowship. This research was supported by NIH Grants HG00209 and HG00376 to M.B., CA39926 and HG00425 to B.S.E., and HD24610 and HG00206 to D.R.C. and R.M.M.

\section{REFERENCES}

Barker, D., Schafer, M., and White, R. (1984). Restriction sites containing CpG show a higher frequency of polymorphism in human DNA. Cell 36: 131-138.

Barker, D., Green, P., Knowlton, R., Schumm, J., Langer, E., Oliphant, A., Willard, H., et al. (1987). Genetic linkage map of human chromosome 7 with 63 DNA markers. Proc. Natl. Acad. Sci. USA 84: 8006-8010.

Bishop, D. T., and Crockford, G. P. (1992). Comparisons of radiation hybrid mapping and linkage mapping. Cytogenet. Cell Genet. 59: 93-95.

Boehnke, M., Lange, K., and Cox, D. R. (1991). Statistical methods for multipoint radiation hybrid mapping. Am. J. Hum. Genet. 49: 1174-1188.

Budarf, M., Canaani, E., and Emanuel, B. S. (1988). Linear order of the four BCR-related loci in 22q11. Genomics 3: 168-171.

Budarf, M., Emanuel, B. S., Mohandas, T., Goeddel, D. V., and Lowe, D. G. (1989). Human differentiation-stimulating factor (leukemia inhibitory factor, human interleukin DA) gene maps distal to the Ewing sarcoma breakpoint on 22q. Cytogenet. Cell Genet. 52: 19-22.

Budarf, M. L., McDermid, H. E., Sellinger, B., and Emanuel, B. S. (1991). Isolation and regional localization of 35 anonymous DNA markers for human chromosome 22. Genomics 10: 996-1002.

Burmeister, M., Suwon, K., Price, E. R., De Lange, T., Tantravahi, U., Myers, R. M., and Cox, D. R. (1991). A map of the distal region of the long arm of human chromosome 21 constructed by radiation hybrid mapping and pulsed-field gel electrophoresis. Genomics 9: $19-30$.

Chakravarti, A., and Reefer, J. E. (1992). A theory for radiation hybrid (Goss-Harris) mapping: Application to proximal 21q markers. Cytogenet. Cell Genet. 59: 99-101.

Cox, D. R., Burmeister, M., Price, E. R., Kim, S., and Myers, R. M. (1990). Radiation hybrid mapping: A somatic cell genetic method for constructing high resolution maps of mammalian chromosomes. Science 250: 245-250.

Cox, D. R., Pritchard, C. A., Uglum, E., Casher, D., Kobori, J., and Myers, R. M. (1989). Segregation of the Huntington disease region of human chromosome 4 in a somatic cell hybrid. Genomics 4: 397407.

Croce, C. M., Huebner, K., Isobe, M., Fainstain, E., Lifshitz, B., Shitivelman, E., and Canaani, E. (1987). Mapping of four distinct BCRrelated loci to chromosome region 22q11: Order of BCR loci relative to chronic myelogenous leukemia and acute lymphoblastic leukemia breakpoints. Proc. Natl. Acad. Sci. USA 84: 7174-7178.

Delattre, O., Azambuja, C. J., Aurias, A., Zucman, J., Peter, M., Zhang, F., Hors-Cayla, M. C., Rouleau, G., and Thomas, G. (1991). Mapping of human chromosome 22 with a panel of somatic cell hybrids. Genomics 9: 721-727.

Dumanski, J. P., Carlbom, E., Collins, V. P., Nordenskjold, M., Emanuel, B. S., Wolff, R., O'Connell, P., White, R., Lalouel, J.-M., and Leppert, M. (1991). A map of 22 loci on human chromosome 22. Genomics 11: 709-719.
Falk, C. T. (1991). A simple method for ordering loci using data from radiation hybrids. Genomics 9: 120-123.

Feinberg, A. P., and Vogelstein, B. (1984). A technique for labeling restriction endonuclease fragments to high specific activity: Addendum. Anal. Biochem. 137: 266-267.

Green, P. (1992). Construction and comparison of chromosome 21 radiation hybrid and linkage maps using CRI-MAP. Cytogenet. Cell Genet. 59: 122-124.

Julier, C., Lathrop, G. M., Reghis, A., Szajnert, M. F., Lalouel, J. M., and Kaplan, J. C. (1988). A linkage and physical map of chromosome 22, and some applications to gene mapping. Am. J. Hum. Genet. 42: 297-308.

Lawrence, S., Morton, N. E., and Cox, D. R. (1991). Radiation hybrid mapping. Proc. Natl. Acad. Sci. USA 88: 7477-7480.

Ledbetter, S. A., Garcia-Heras, J., and Ledbetter, D. H. (1990). PCRkaryotype of human chromosomes in somatic cell hybrids. Genomics 8: 614-622.

Lowe, D. F., Nunes, W., Bombara, M., McCabe, S., Ranges, G. E., Henzel, W., Tomida, M., Yamaguchi, Y. Y., Hozumi, M., and Goeddel, D. V. (1989). Genomic cloning and heterologous expression of human differentiation-stimulation factor. DNA 8: 351-359.

Martuza, R. L., and Eldridge, R. E. (1988). Neurofibromatosis 2 (bilateral acoustic neurofibromatosis). N. Engl. J. Med. 318: 684-688.

Richard, C. W., III, Withers, D. A., Meeker, T. C., Maurer, S., Evans, G. A., Myers, R. M., and Cox, D. R. (1991). A radiation hybrid map of the proximal long arm of human chromosome 11 containing the multiple endocrine neoplasia type 1 (MEN-1) and bcl-1 disease loci. Am. J. Hum. Genet. 49: 1189-1196.

Rouleau, G. A., Kurnit, D. M., Neve, R. L., Bazanowsky, A., Patterson, D., and Gusella, J.F. (1988). D22S15-a fetal brain cDNA with BanII and SacI RFLP. Nucleic Acids Res. 16: 1648.

Rouleau, G. A., Haines, J. L., Bazanowski, A., Colella, C. A., Trofatter, J. A., Wexler, N. S., Conneally, P. M., and Gusella, J. F. (1989). A genetic linkage map of the long arm of human chromosome 22. Genomics 4: 1-6.

Rouleau, G. A., Seizinger, B. R., Wertelecki, W., Haines, J. L., Superneau, D. W., Martuza, R. L., and Gusella, J. F. (1990). Flanking markers bracket the neurofibromatosis type 2 (NF2) gene on chromosome 22. Am. J. Hum. Genet. 46: 323-328.

Seizinger, B. R., Martuza, R. L., and Gusella, J. F. (1986). Loss of genes on chromosome 22 in tumorigenesis of human acoustic neuroma. Nature 322: 644-647.

Seizinger, B. R., de la Monte, S., Atkins, L., Gusella, J. F., and Martuza, R. L. (1987). Molecular genetic approach to human meningioma: Loss of genes on chromosome 22. Proc. Natl. Acad. Sci. USA 84: $5419-5423$.

Selleri, L., Hermanson, G. G., Eubanks, J. H., Lewis, K. A., and Evans, G. A. (1991). Molecular localization of the t(11;22)(q24; q12) translocation of Ewing sarcoma by chromosomal in situ suppression hybridization. Proc. Natl. Acad. Sci. USA 88: 887-891.

Van Keuren, M., Hart, I. M., Kao, F. T., Neve, R. L., Bruns, G. A., Kurnit, D. M., and Patterson, D. (1987). A somatic cell hybrid with a single human chromosome 22 corrects the defect in the $\mathrm{CHO}$ mutant ( Ade $\left.^{-} \mathrm{I}\right)$ lacking adenylosuccinase activity. Cytogenet. Cell Genet. 44: 142-147.

Weller, P., Jeffreys, A. J., Wilson, V., and Blanchetot, A. (1984). Organisation of the human myoglobin gene. EMBO J. 3: 439-446.

Zankl, H., and Zang, K. D. (1972). Cytological and cytogenetical studies on brain tumors. Humangenetik 14: 167-169. 